\title{
Study on the Optimal Production Pressure of Different Types of Natural Gas Hydrate Based on Formation Stability
}

\author{
Ting Sun, ${ }^{1}$ Yuan Chen $\mathbb{D}^{1},{ }^{1}$ Jin Yang, ${ }^{1}$ Qingping Li, ${ }^{2}$ and Weixin Pang $^{2}$ \\ ${ }^{1}$ China University of Petroleum-Beijing, 102249, China \\ ${ }^{2}$ CNOOC Research Institute co. LTD-State Key Laboratory of Natural Gas Hydrates, 10028, China \\ Correspondence should be addressed to Yuan Chen; 18810906492@163.com
}

Received 4 June 2020; Revised 7 September 2020; Accepted 14 September 2020; Published 23 October 2020

Academic Editor: Judit Mádl-Szonyi

Copyright @ 2020 Ting Sun et al. This is an open access article distributed under the Creative Commons Attribution License, which permits unrestricted use, distribution, and reproduction in any medium, provided the original work is properly cited.

\begin{abstract}
Natural gas hydrate is an ice-like crystal formed by methane and water, which is a new type of strategic energy with huge reserves. The exploitation of deep-sea hydrate will cause a large amount of decomposition of hydrate, which will decrease the sediment strength. In this paper, production models of different types of hydrate reservoirs under different BHP (bottom hole pressure) were established. Then, sensitivity analysis was conducted to determine parameters which have the most significant influence on formation subsidence. After that, hydrate formation failure was discussed using two different criteria: formation subsidence and stress-strain curve. Then, critical production pressure was determined. Through comparison, it was found that the criterion of formation subsidence is more suitable. Finally, based on this criterion, the optimal production pressure of different types of hydrate reservoir was determined. The work of this paper will provide a certain reference value for the efficient and safe production of hydrate in the future.
\end{abstract}

\section{Introduction}

Natural gas hydrate (NGH) is considered as the most promising new strategic energy [1]. Solid gas hydrate is usually a cemented component of the reservoir, and its decomposition will cause a series of changes in reservoir physical parameters, mechanical properties, and pore pressure [2]. A large number of experimental and numerical simulation studies have shown that hydrate decomposition leads to a significant increase in the physical parameters such as reservoir porosity and permeability, and the mechanical parameters such as elastic modulus and cohesion are significantly reduced.

The research of NGH has drawn more and more attention all over the world recently. Research on hydrate production mainly focuses on the effect of production parameters on gas production and decomposition rate. For example, Fitzgerald and Castaldi conducted electric heating mining experiments in a large laboratory reactor with a volume of $59.3 \mathrm{~L}$, and the results showed that the production efficiency was relatively high at the initial stage of mining and then declined. When hydrate saturation was high, the energy utilization ratio was higher, and the influence of hydrate saturation on mining efficiency was greater than that of heating power [3]. Yousif et al. established a three-phase model of onedimensional isothermal depressurization exploitation of hydrate and compared it with experimental results. It is found that the greater the pressure difference, the faster the hydrate decomposition [4]. Falser et al. analysed simple depressurization and combined method of depressurization and electric heating. The results showed that with the same production pressure, combined method increased the gas production by 1.8 times compared with simple depressurization [5].

Moreover, for the mechanical response of hydrate sediments during exploitation, there are many experimental and numerical researches. Priest et al. analysed the process of hydrate formation and decomposition through hydrate resonance column experiment. The results showed that hydrate decomposition could significantly reduce the stiffness and strength of sediments, and the degree of reduction depended on the interaction between hydrate and sediments [6]. Rutqvist et al. combined TOUGH+HYDRATE and 
FLAC3D to analyse hydrate decomposition and formation deformation. The results showed that shear failure occurred in the horizontal well, while the formation subsided around the vertical well. The shear failure and the vertical subsidence were more obvious at the wellhead [7]. UC Berkeley laboratory studied the mechanical properties of hydrates during decomposition, which coupled friction angle, cohesion, bulk modulus, and shear strength in its simulations [8]. However, experiments can only obtain the elastic properties, while the formation deformation is elastic-plastic during production, and synthetic samples are different from the hydrate in actual formation, which will cause inaccurate results. On the other hand, numerical simulations mainly focus on the cumulative gas production or the change of mechanical properties during exploitation. There are few researches which considered both production and mechanical properties.

From the above, the exploitation of hydrate will cause formation deformation, even formation failure, and there is no research focus on the relationship between production rate and mechanical properties, that is, it is necessary to study the optimal production pressure to maximize gas production and keep the formation stable.

In this paper, the multiphase seepage and formation stability during hydrate exploitation were taken as the core issues, and the depressurization process of hydrate was studied by combining theoretical analysis with numerical simulation. Based on the mechanism and the law of formation failure, criteria and critical condition of formation failure were determined, and the optimal production pressure for safe and stable exploitation was obtained for hydrate reservoirs of different distribution patterns.

\section{Materials and Methods}

2.1. Distribution Modes of Natural Gas Hydrate. There are mainly six distribution patterns of hydrate in sediments according to hydrate saturation, including pore-filling mode, contact cementation mode, particle-wrapping mode, skeleton/particle-supporting mode, mixed mode, and nodule/crack-filling mode, as shown in Figure 1. Generally, hydratebearing sediments is relatively shallow, uncompacted, and weakly consolidated, whose strength is mainly determined by hydrate content and distribution pattern. The strength of pore-filling mode is the lowest, contact cementation mode is higher, and particle-wrapping mode is the strongest.

Due to various distribution patterns of hydrate in formation pores, its multiphase seepage and mechanical properties in the formation are very special. Hydrate saturation corresponding to different distribution patterns is different. When the saturation is high, the cementation effect of hydrates is relatively more obvious, and the mechanical strength of the formation after decomposition will be significantly affected. However, when the saturation is low, the support of hydrates on the formation is relatively weak [9]. According to previous research results, when hydrate saturation is less than $20 \%$, the distribution of hydrates in the formation is mainly porefilling mode, which has little effect on sediment strength; when saturation is greater than $40 \%$, the sediment strength is enhanced significantly, and hydrate decomposition will greatly weaken the formation strength [10]. Laboratory experiments show that the mechanical strength of hydrate sediment increases with hydrate saturation $[11,12]$.

The distribution pattern of hydrate in formation is related to the sedimentary environment and fluid migration channel. Previous studies have shown that hydrates are formed in pore fluids first and then gradually move towards the rock skeleton. After saturation exceeds 30\%, formation particles are gradually cemented. However, in this case, part of the gas is trapped, resulting in the lack of gas source to continue to form hydrate. Therefore, the hydrate saturation in formation is up to $70 \%$ [13].

Different distribution patterns of hydrate in sediments lead to different formation response after decomposition. Therefore, for different types of hydrate reservoirs, the optimal production pressure should be calculated separately. In this paper, three different types of hydrate reservoirs are mainly studied: contact cementation mode, particle-wrapping mode, and skeleton-supporting mode. As mentioned before, when hydrate saturation is greater than $40 \%$, the formation strength is enhanced significantly. So, we assume the saturation of contact cementation mode is $40 \%$ for its strength is higher than modes (d), (e), and (f). From Figure 1, we can see that the saturation of skeleton-supporting mode is the highest, that is, $70 \%$, which is the maximum saturation of hydrate reservoir. As for the particle-wrapping mode, the saturation is between the above two modes, so we assumed it to be $60 \%$. Therefore, the initial hydrate saturation of these three modes is assumed to be $40 \%, 60 \%$, and $70 \%$, respectively. These values are assumed based on previous study, which need to be further verified through experiments.

2.2. Theoretical and Numerical Model of Hydrate Production. Theoretical equations of hydrate in the process of decomposition are as follows:

(1) Kinetic equation of hydrate decomposition [15]

$$
m_{g}=K_{\mathrm{rd}} M_{g} A_{\mathrm{dec}}\left(\theta_{e} p_{e}-\theta_{g} p_{g}\right)
$$

where $m_{g}$ is the decomposition rate of natural gas in porous reservoir per unit volume, $\mathrm{kg} /\left(\mathrm{m}^{3} \bullet \mathrm{s}\right) ; K_{\mathrm{rd}}$ is the hydrate decomposition rate constant, which is related to temperature, $\mathrm{mol} /\left(\mathrm{m}^{2} \cdot \mathrm{Pa} \bullet \mathrm{s}\right) ; M_{\mathrm{g}}$ is the molar mass of $\mathrm{CH}_{4} ; A_{\mathrm{dec}}$ is the surface area of decomposed hydrate in porous media of unit volume, $\mathrm{m}^{-1} ; \theta_{e}$ is the fugacity coefficient at equilibrium pressure; $p_{e}$ is the equilibrium pressure under current temperature, $\mathrm{Pa} ; \theta_{g}$ is the fugacity coefficient under current pressure; $p_{g}$ is the current gas pressure.

(2) Energy conservation equation [15]

$$
\begin{gathered}
\frac{\partial}{\partial \mathrm{t}}\left[(1-\varphi) \rho_{r} H_{r}+\varphi S_{h} \rho_{h} H_{H}+\varphi S_{g} \rho_{g} H_{g}+\varphi S_{w} \rho_{w} H_{w}\right] \\
\quad=\nabla \cdot\left(K_{\mathrm{c}} \nabla T\right)-\nabla \cdot\left(\rho_{g} \bar{u}_{g} H_{g}+\rho_{\mathrm{w}} \bar{u}_{\mathrm{w}} H_{w}\right)+Q_{\text {in }},
\end{gathered}
$$


where $\rho_{r, h, g, w}$ are the density of rock, hydrate, gas, and water; $H_{r, H, g, w}$ are the enthalpy of rock, hydrate, gas, and water; $\bar{u}_{g}$, $\bar{u}_{w}$ represent the flow rate of gas and water; $K_{c}$ is the effective heat transfer coefficient for hydrate reservoir; $T$ is the temperature; $Q_{\text {in }}$ is the outside heat supply.

(3) Mass conservation equation [16]

$$
\begin{gathered}
-\left[\frac{\partial\left(\rho_{w} \overrightarrow{v_{w}}\right)}{\partial x}+\frac{\partial\left(\rho_{g} \overrightarrow{v_{g}}\right)}{\partial x}\right]+m_{w}+m_{g}-m_{h} \\
=\frac{\partial\left(\varphi S_{w} \rho_{w}+\varphi S_{g} \rho_{g}+\varphi S_{h} \rho_{h}\right)}{\partial t},
\end{gathered}
$$

where $\rho_{w}, \rho_{g}, \rho_{h}$ represent the density of water, methane, and hydrate, $\left(\mathrm{kg} / \mathrm{m}^{3}\right) ; \overrightarrow{v_{w}}, \overrightarrow{v_{g}}$ represent water and methane seepage velocity, $\mathrm{m} / \mathrm{s} ; m_{w}, m_{g}, m_{h}$ represent the mass of water and methane produced and the mass of hydrate consumed by decomposition within unit time, $\mathrm{kg} /\left(\mathrm{m}^{3} \cdot \mathrm{s}\right) ; S_{w}, S_{g}, S_{h}$ represent the saturation of water, methane, and hydrate. $\varphi$ is the porosity.

(4) Gas-water two phase fluid-solid coupling seepage equation [16]

$$
\frac{\partial\left(\varphi \rho_{g} S_{g}\right)}{\partial \mathrm{t}}-\Delta \cdot\left[\frac{K_{r g} \rho_{g}}{\mu_{g}} K\left(\Delta p_{g}+\rho_{g} g\right)\right]+\left(\varphi \rho_{g} S_{g}\right) \Delta \cdot v_{s}=m_{g}+q_{g} \text {, }
$$

$\frac{\partial\left(\varphi \rho_{w} S_{w}\right)}{\partial \mathrm{t}}-\Delta \cdot\left[\frac{K_{r w} \rho_{w}}{\mu_{w}} K\left(\Delta p_{w}+\rho_{w} g\right)\right]+\left(\varphi \rho_{w} S_{w}\right) \Delta \cdot v_{s}=m_{w}+q_{w}$.

(5) Equilibrium differential equation of deforming medium [16]

$$
\begin{aligned}
& \frac{\partial \sigma_{\mathrm{x}}}{\partial \mathrm{x}}+\frac{\partial \tau_{\mathrm{xy}}}{\partial \mathrm{y}}+\frac{\partial \tau_{\mathrm{xz}}}{\partial \mathrm{z}}+f_{\mathrm{x}}-\alpha \frac{\partial \overline{\mathrm{p}}}{\partial \mathrm{x}}=0, \\
& \frac{\partial \sigma_{\mathrm{y}}}{\partial \mathrm{y}}+\frac{\partial \tau_{\mathrm{xy}}}{\partial \mathrm{x}}+\frac{\partial \tau_{\mathrm{yz}}}{\partial \mathrm{z}}+f_{\mathrm{y}}-\alpha \frac{\partial \overline{\mathrm{p}}}{\partial \mathrm{y}}=0, \\
& \frac{\partial \sigma_{\mathrm{z}}}{\partial \mathrm{z}}+\frac{\partial \tau_{\mathrm{xz}}}{\partial \mathrm{x}}+\frac{\partial \tau_{\mathrm{yz}}}{\partial \mathrm{y}}+f_{\mathrm{z}}-\alpha \frac{\partial \overline{\mathrm{p}}}{\partial \mathrm{z}}=0 .
\end{aligned}
$$

(6) Geometric equation [17]

$$
\left\{\begin{array}{c}
\varepsilon_{x} \\
\varepsilon_{y} \\
\varepsilon_{z} \\
\gamma_{x y} \\
\gamma_{y z} \\
\gamma_{z x}
\end{array}\right\}=\left[\begin{array}{c}
\frac{\partial u}{\partial x} \\
\frac{\partial v}{\partial y} \\
\frac{\partial w}{\partial z} \\
\frac{\partial u}{\partial y}+\frac{\partial v}{\partial x} \\
\frac{\partial v}{\partial z}+\frac{\partial w}{\partial y} \\
\frac{\partial w}{\partial x}+\frac{\partial u}{\partial z}
\end{array}\right]=\left[\begin{array}{ccc}
\frac{\partial}{\partial x} & 0 & 0 \\
0 & \frac{\partial}{\partial y} & 0 \\
0 & 0 & \frac{\partial}{\partial z} \\
\frac{\partial}{\partial y} & \frac{\partial}{\partial x} & 0 \\
0 & \frac{\partial}{\partial z} & \frac{\partial}{\partial y} \\
\frac{\partial}{\partial z} & 0 & \frac{\partial}{\partial x}
\end{array}\right]\left\{\begin{array}{c}
u \\
v \\
w
\end{array}\right\} .
$$

Based on these above equations, a horizontally homogeneous model of hydrate is established to perform production simulations.

In this paper, hydrate production simulations are conducted in three groups: initial hydrate saturation $=40 \%$, $60 \%$, and $70 \%$, which represent three different distribution patterns of hydrate. Simulations of each group are carried out under different $\mathrm{BHP}$, that is, $\mathrm{BHP}=1000 \mathrm{kPa}, 2000 \mathrm{kPa}$, $3000 \mathrm{kPa}, 4000 \mathrm{kPa}$, and $5000 \mathrm{kPa}$, because different BHP lead to different decomposition rate of hydrate and then different formation response.

The geological model of hydrate exploitation is established by the CMG software, which couples multiphase seepage and geomechanics. The size of numerical model is $300 \mathrm{~m} \times 300 \mathrm{~m} \times 120 \mathrm{~m}$, and the depth of reservoir top is $450 \mathrm{~m}$, as shown in Figure 2. The hydrate layer is $90 \mathrm{~m}$ thick with $30 \mathrm{~m}$ of rock layers above and below. The production well is set in the middle of the model. The parameters of the model are shown in Table 1. The initial formation pressure is $7800 \mathrm{kPa}$ (the depth of reference block is $450 \mathrm{~m}$ ), and the initial formation temperature is $10 \mathrm{C}$.

The simulation models are initialised by assuming no gravity, no secondary hydrate, no capillary pressure, and only water and methane are produced by decomposition. For each simulation, formation subsidence and gas production are calculated and the maximum subsidence is recorded. The results are expected to show optimal production pressure of different types of natural gas hydrate based on two different criteria.

2.3. Sensitivity Analysis. After the model is established, we do sensitivity analysis first. Formation sensitivity is an important factor directly affecting the productivity of reservoir, as well as an important content in the study of reservoir damage degree.

The objective function $y$ is subsidence, and the influence of various parameters $\left(x_{i}\right)$ on the objective function is represented by the following reduced quadratic model, which considers the linear effects (through linear terms), the interaction effects (through cross terms $x_{i} x_{j}$ ), and the quadratic effects (through quadratic terms $x_{j}^{2}$ ) [18].

$$
y=a_{0}+\sum_{j=1}^{k} a_{j} x_{j}+\sum_{j=1}^{k} a_{\mathrm{jj}} x_{j}^{2}+\sum_{i<j} \sum_{j=2}^{k} a_{\mathrm{ij}} x_{i} x_{j}
$$

$x_{i}$ includes: 


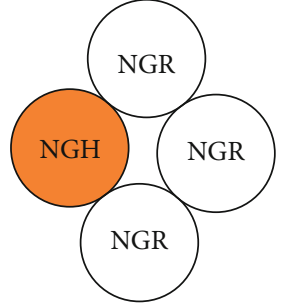

(a)

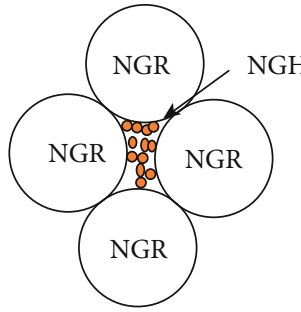

(d)

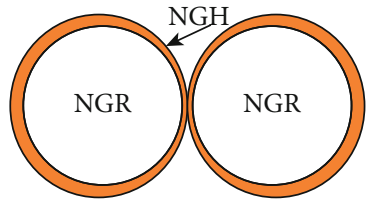

(b)

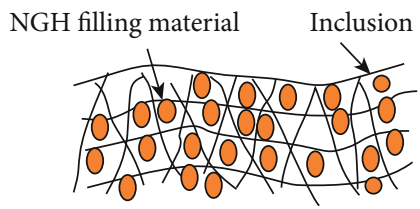

(e)

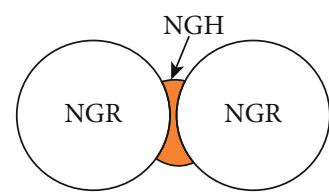

(c)

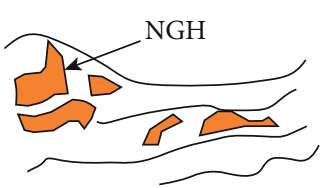

(f)

Figure 1: Distribution pattern of hydrate in sediments. (a) Skeleton-supporting mode. (b) Particle-wrapping mode. (c) Contact cementation mode. (d) Pore-filling mode. (e) Mixed mode. (f) Nodule/crack-filling mode. NGR: natural gas hydrate-bearing rock; NGH: natural gas hydrate $[13,14]$.

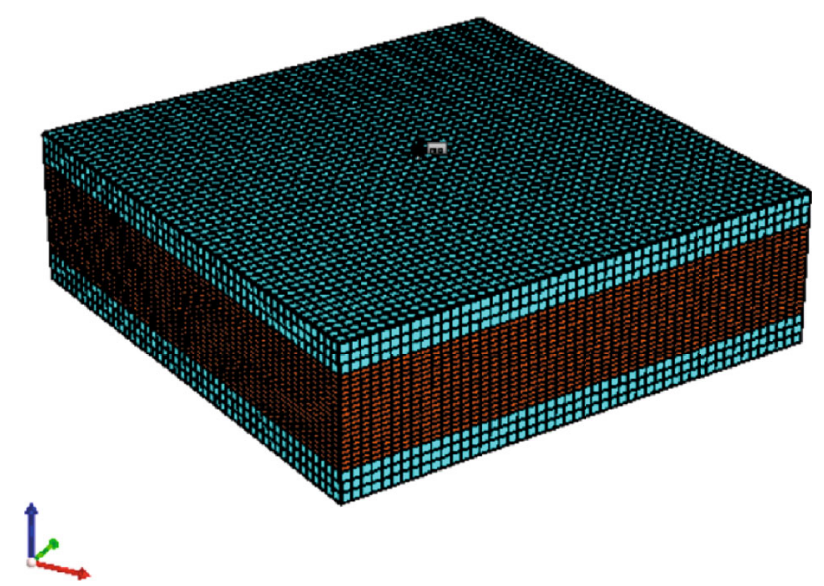

Figure 2: Geological model of hydrate exploitation.

(1) BHP: When exploiting hydrate by depressurization method, BHP has great influence on gas production rate and mechanical behaviour of formation. In this paper, $\mathrm{BHP}$ is assumed to range from $1000 \mathrm{kPa}$ to $5000 \mathrm{kPa}$

(2) Injected Heat: Injecting heat into hydrate formation can improve formation temperature and increase the decomposition rate of hydrate to some extent, thus affecting formation subsidence. In this paper, injected heat is assumed to vary from 0 to $8 \times 10^{10} \mathrm{~J}$ /day

(3) Reservoir Depth: With different reservoir depth, the overlying formation will exert different forces on hydrate layer, which will have corresponding influ- ence on formation subsidence. In this paper, reservoir depth is assumed to vary from $450 \mathrm{~m}$ to $1000 \mathrm{~m}$

(4) Hydrate Saturation: Hydrate saturation represents the content of hydrate in formation pores, which is closely related to formation strength. With different hydrate saturation, the change of gas production rate, effective stress, and other parameters with time will be different, thus affecting formation subsidence. In this paper, the range of hydrate saturation is assumed from $30 \%$ to $70 \%$

The effect of interaction terms and quadratic terms can be understood by looking as the effect of " $\mathrm{A} * \mathrm{~B}$ " on the subsidence in Figure 3. For example, we assume ranges of "BHP" and " $\mathrm{S}_{\mathrm{h}}$ " as $(a, b)$ and $(c, d)$. The maximum subsidence occurs at $\left(\mathrm{BHP}=a, S_{h}=d\right)$ or $\left(\mathrm{BHP}=b, S_{h}=c\right)$, while the minimum subsidence occurs at $\left(\mathrm{BHP}=a, S_{h}=c\right)$ or $\left(\mathrm{BHP}=b, S_{h}=d\right)$. The difference between these two values of subsidence is $0.0485 \mathrm{~m}$.

Figure 3 shows that in all simulation results, the relative effect of BHP and hydrate saturation on the subsidence is greater than that of injected heat and depth. BHP has the greatest influence on subsidence: the lower BHP, the greater the subsidence, and more prone to failure. In all simulation results, the maximum subsidence is about $0.1 \mathrm{~m}$. When BHP increased from $1000 \mathrm{kPa}$ to $5000 \mathrm{kPa}$, formation subsidence decreased by $0.06 \mathrm{~m}$. The increase of hydrate saturation also reduces subsidence. Other terms have little influence on the objective function and can be ignored.

For actual exploitation, initial hydrate saturation is an immutable parameter, while BHP can be changed. Therefore, in order to ensure safe and efficient production, it is necessary to optimize BHP in hydrate reservoirs with different saturation, so as to maximize gas production and control the formation subsidence within a safe range. 
TABLE 1: Parameters of the hydrate-bearing sediment model.

\begin{tabular}{lc}
\hline Parameter & Value \\
\hline Thickness of the upper rock strata, m & 30 \\
Depth of the top of reservoir, m & 450 \\
Thickness of the lower rock strata, m & 30 \\
Thickness of hydrate layer, m & 90 \\
Initial hydrate saturation of hydrate layer & $0.7 / 0.6 / 0.4$ \\
Initial water saturation of hydrate layer & $0.3 / 0.4 / 0.6$ \\
Porosity of hydrate layer & 0.25 \\
Permeability of hydrate layer, md & $K_{i}=K_{j}=125, K_{k}=12.5$ \\
Initial temperature, C & 10 \\
Initial pressure, $\mathrm{kPa}$ & 7800 \\
\hline
\end{tabular}

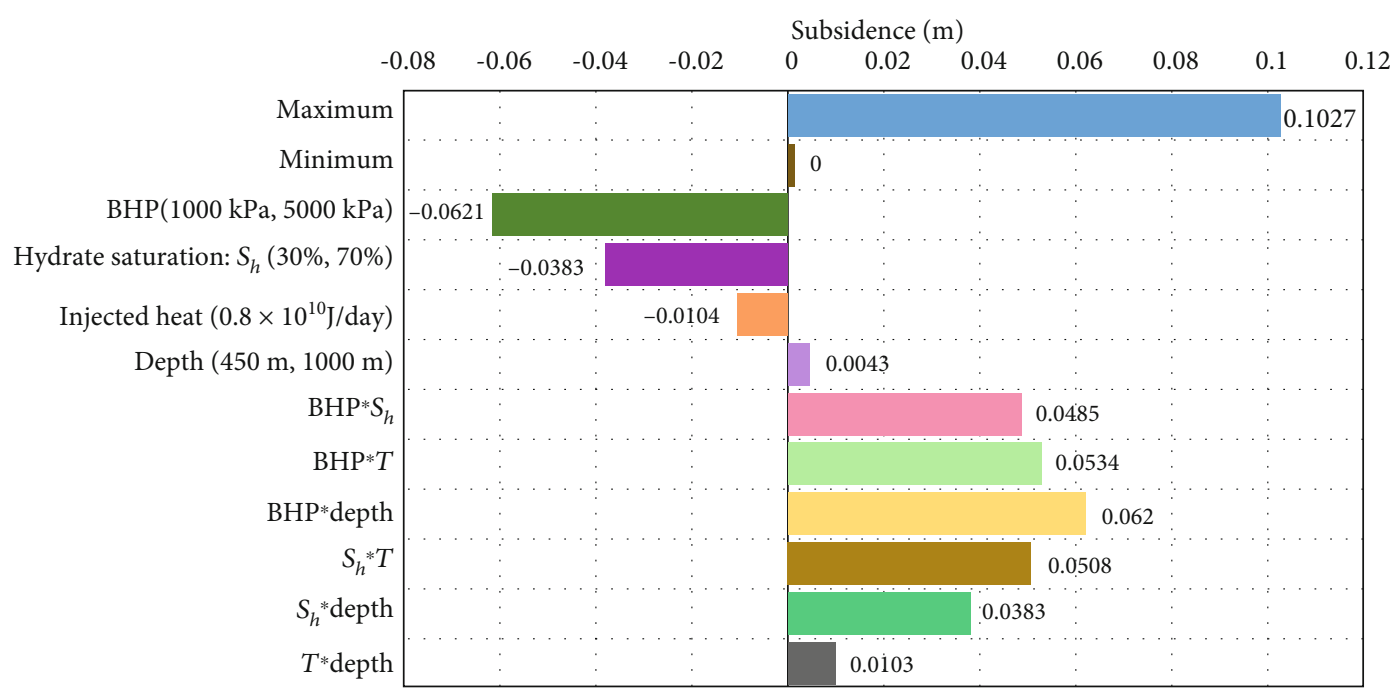

FIGURE 3: Relative effects of various parameters on the subsidence of hydrate formation.

\section{Results and Discussion}

Depressurization method is the most commonly used and economical method for hydrate exploitation. Decreasing BHP can accelerate hydrate decomposition, but when pressure difference between BHP and formation pressure is too large, a great amount of gas will be produced from hydrate, which will lead to a sharp increase in effective stress of the formation and then formation failure. Therefore, we need to determine optimal production pressure of different types of hydrate reservoir to ensure safe and efficient production.

The critical production pressure should be determined first. In this paper, we use two ways to determine the critical condition of formation failure, that is, method based on formation subsidence and method based on stress-strain curve.

3.1. Based on the Formation Subsidence. During production, it is normal that slight formation subsidence occurs due to the change of pore pressure. However, if the subsidence is greater than the critical value, it may exert a large force on production equipment, causing damage to the equipment.
In this paper, the model size is small compared with actual hydrate-bearing formation, so it is considered that formation failure occurs when the vertical subsidence exceeds $60 \mathrm{~mm}$, that is, $60 \mathrm{~mm}$ is the critical subsidence of formation failure. This critical subsidence is an assumed value for calculation in this paper and needs to be corrected according to further mechanical experiments.

Coupled geomechanical models were established for three types of hydrate reservoirs, and exploitation was simulated under production pressure of $1000 \mathrm{kPa}, 2000 \mathrm{kPa}$, $3000 \mathrm{kPa}, 4000 \mathrm{kPa}$, and $5000 \mathrm{kPa}$, respectively. The production time was assumed to be 1100 days. The curve of maximum formation subsidence with production time in each case was shown in Figures 4-6.

For reservoir with an initial hydrate saturation of $40 \%$ (the hydrate distribution mode is contact cementation), when production pressure is greater than $4000 \mathrm{kPa}$, the maximum formation subsidence is less than the critical value (see Figure 4), that is, formation failure does not occur in the simulated process. When production pressure is less than $4000 \mathrm{kPa}$, namely $\mathrm{BHP}=1000 \mathrm{kPa}, 2000 \mathrm{kPa}$, and $3000 \mathrm{kPa}$, 


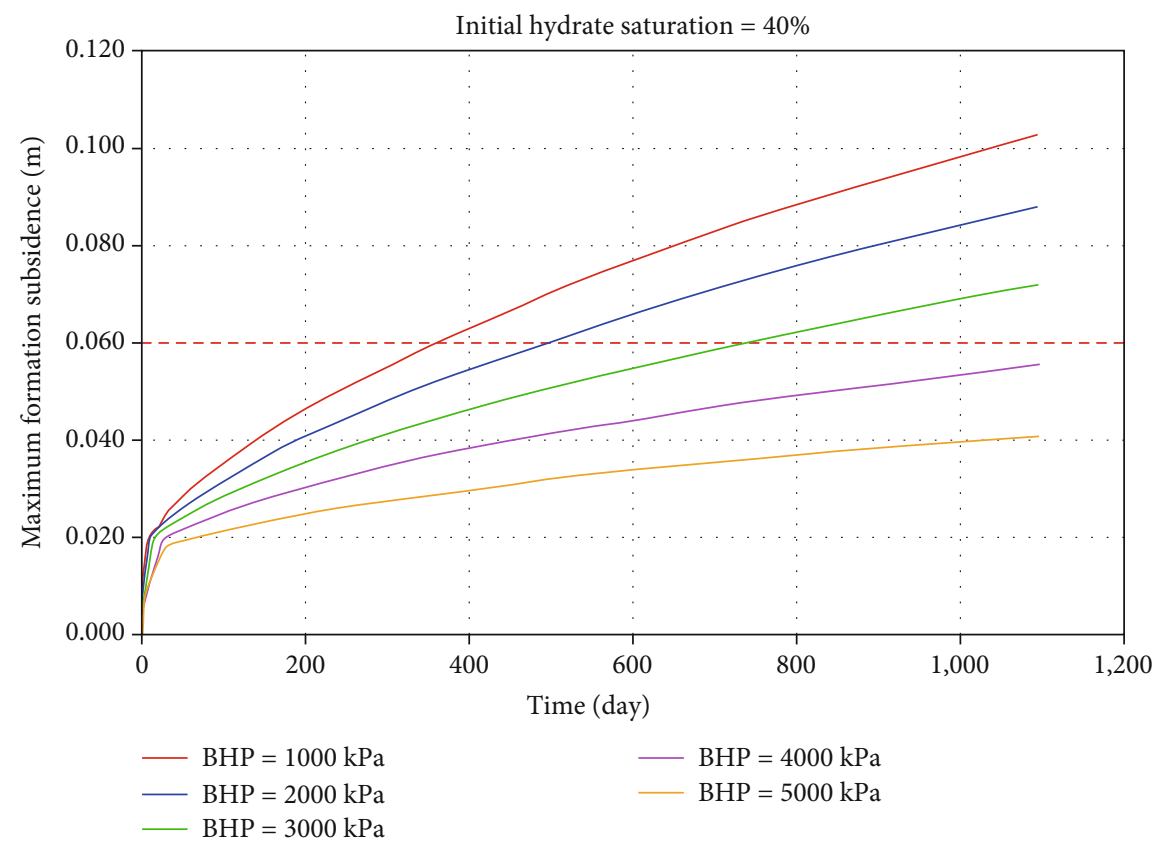

FIGURE 4: The subsidence of contact cementation reservoir varies with production pressure.

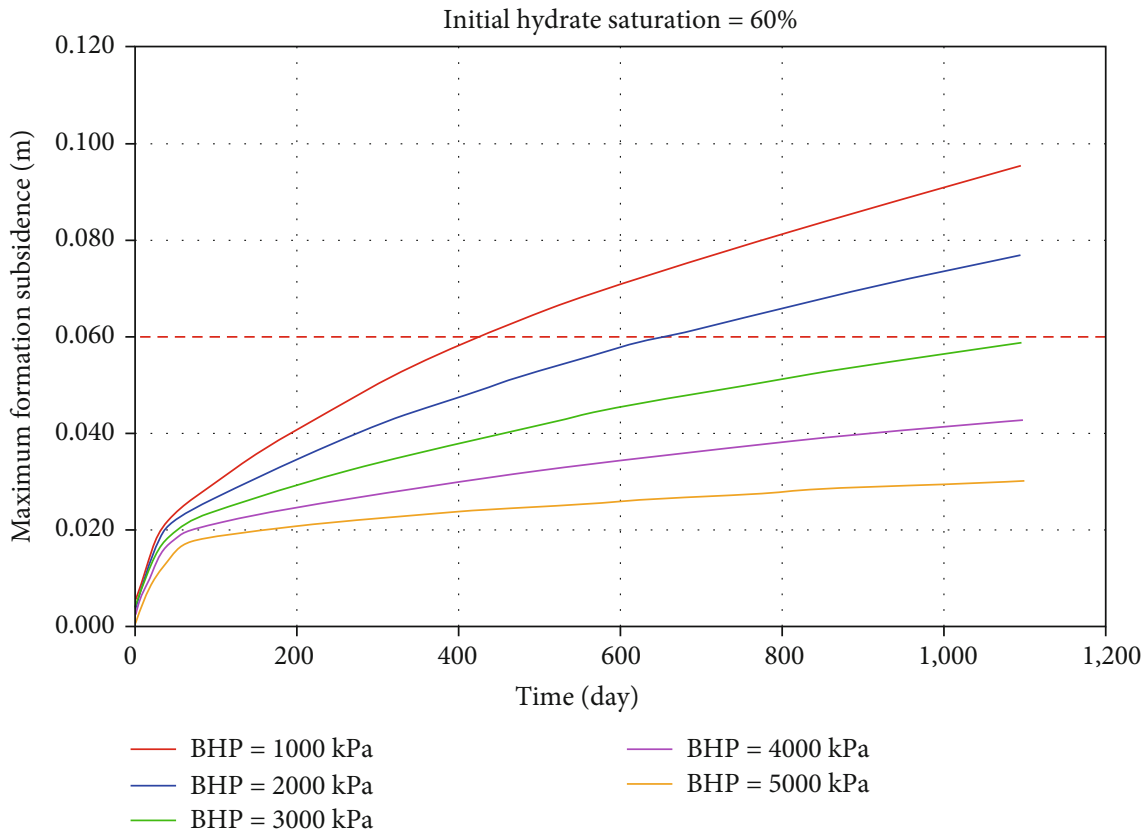

Figure 5: The subsidence of particle-wrapping hydrate reservoir varies with production pressure.

the critical formation subsidence is reached on the 360th, 500th, and 750th days, respectively, which is considered as formation failure.

For reservoir with an initial hydrate saturation of $60 \%$ (the hydrate distribution mode is particle wrapping), when production pressure is greater than $3000 \mathrm{kPa}$, the maximum formation subsidence is less than the critical value (see Figure 5), that is, formation failure does not occur in the simulated process. When production pressure is less than $3000 \mathrm{kPa}$, namely $\mathrm{BHP}=1000 \mathrm{kPa}$ and $2000 \mathrm{kPa}$, the critical formation subsidence is reached on the 450th and 650th days, respectively, which is considered as formation failure.

For reservoir with an initial hydrate saturation of $70 \%$ (the hydrate distribution mode is particle supporting), when production pressure is greater than $2000 \mathrm{kPa}$, the maximum formation subsidence is less than the critical value (see Figure 6), that is, formation failure does not occur in the simulated process. When production pressure is less than $2000 \mathrm{kPa}$, namely BHP $=1000 \mathrm{kPa}$, the critical formation subsidence is reached on the 940th day, which is considered as formation failure. 


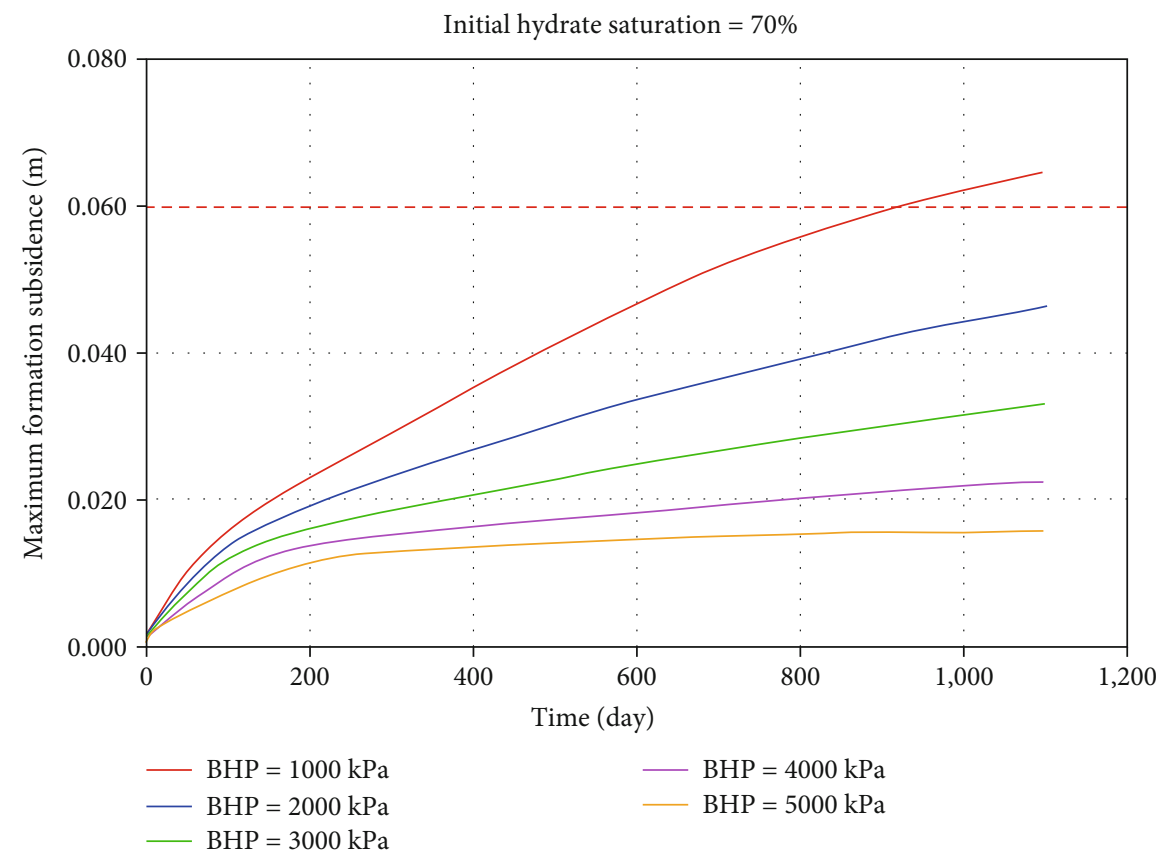

FIGURE 6: The subsidence of skeleton-supporting hydrate reservoir varies with production pressure.

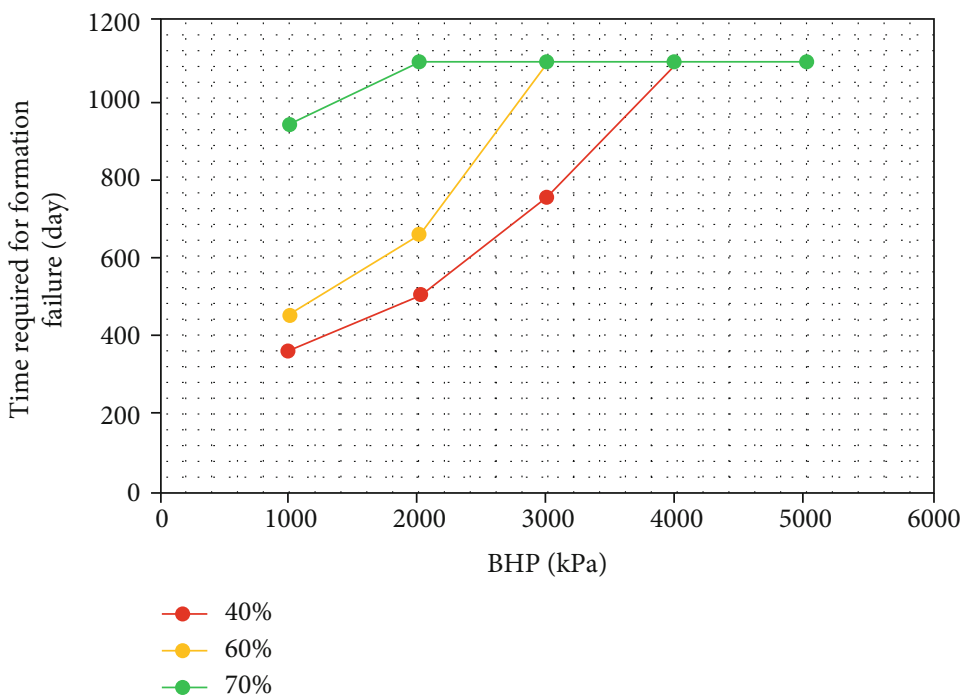

FIGURE 7: Time before formation failure of hydrate with different saturation under different BHP.

Figure 7 shows the time required for formation failure of hydrate with different saturation under different production pressure. It can be seen that for contact cementation formation with an initial saturation of $40 \%$, when BHP is less than $4000 \mathrm{kPa}$, the formation failed before the set production time and production is forced to stop earlier than the end of simulation. Thus, the critical production pressure is $4000 \mathrm{kPa}$. For particle-wrapping formation with an initial saturation of $60 \%$, when BHP is less than $3000 \mathrm{kPa}$, production is forced to stop in advance. The critical production pressure is $3000 \mathrm{kPa}$. For particle-supporting formation with an initial saturation of $70 \%$, when BHP is less than $2000 \mathrm{kPa}$, production is forced to stop in advance, and the critical production pressure is $2000 \mathrm{kPa}$.
If $\mathrm{BHP}$ is greater than the critical value, the length of simulation is considered as the time required for formation failure in order to present the results clearly.

Figure 8 shows the cumulative gas production of three different types of hydrate reservoir at different production pressure during the entire production time (if production is stopped in advance, the cumulative gas production before stop is used). Combined with Figure 7, the optimal production pressure of different types of hydrate reservoir can be obtained, which ensure that the time before formation failure is as long as possible and the cumulative gas production is relatively maximum. When initial hydrate saturation is $40 \%$, the optimal production pressure is $3000 \mathrm{kPa}$, the 


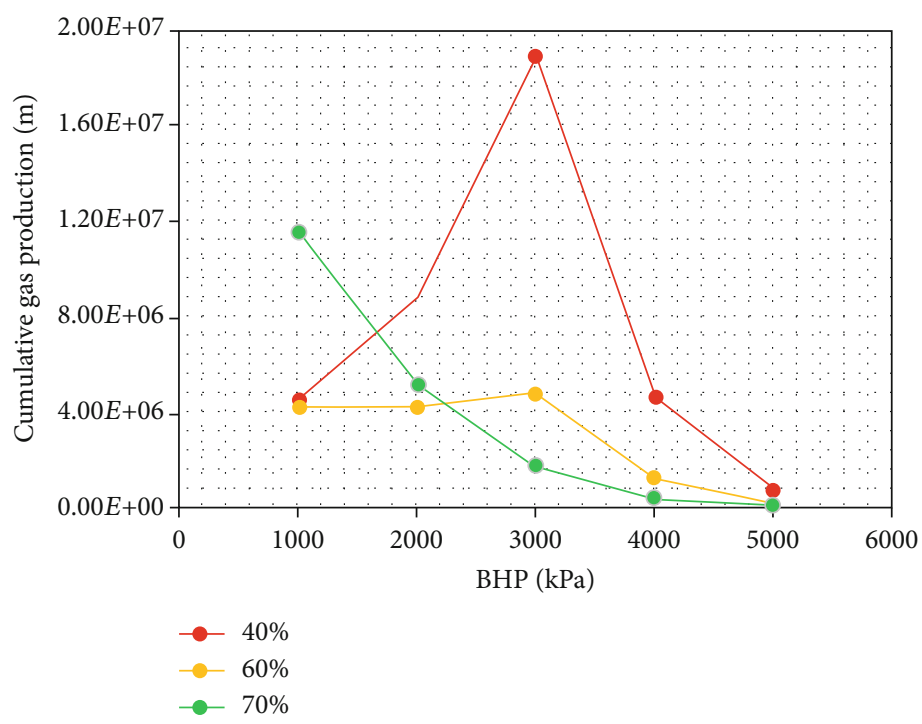

Figure 8: Cumulative gas production before formation failure.

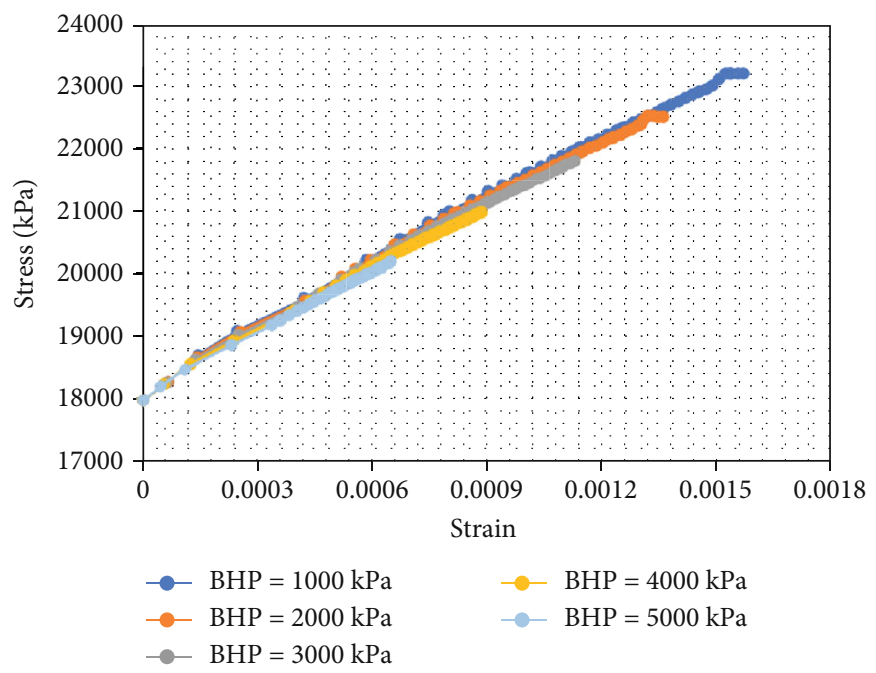

FIgURE 9: The stress-strain curve of contact cementation hydrate reservoir.

cumulative gas production within 1100 days is $1.89 \times 10^{7} \mathrm{~m}^{3}$, and the safe production time is 750 days. When initial hydrate saturation is $60 \%$, the optimal production pressure is $3000 \mathrm{kPa}$, the cumulative gas production within 1100 days is $4.78 \times 10^{6}$ $\mathrm{m}^{3}$, and the safe production time is 1100 days. When initial hydrate saturation is $70 \%$, the optimal production pressure is $1000 \mathrm{kPa}$, the cumulative gas production within 1100 days is $1.15 \times 10^{7} \mathrm{~m}^{3}$, and the safe production time is 940 days.

3.2. Based on the Stress-Strain Curve. During production process, the effective stress of the formation around the well is an important basis for analysing whether formation failure occurs. The change of stress-strain curve reflects the state of formation deformation. When there is an inflection point in the curve, it indicates that the formation has undergone plastic deformation, which means the formation fails, and the inflection point is the critical point of production [17].
Coupled geomechanical models are established for three types of hydrate reservoirs, and the production is simulated under production pressure of $1000 \mathrm{kPa}, 2000 \mathrm{kPa}, 3000 \mathrm{kPa}$, $4000 \mathrm{kPa}$, and $5000 \mathrm{kPa}$, respectively. The formation stressstrain curve in each case is shown in Figures 9-11.

For reservoir with an initial hydrate saturation of $40 \%$ (the hydrate distribution mode is contact cementation), when production pressure is $1000 \mathrm{kPa}$ and $2000 \mathrm{kPa}$, the inflection point appears in the stress-strain curve (see Figure 9), which is considered that the formation fails. However, when the production pressure is greater than $3000 \mathrm{kPa}$, there is no inflection point in the curve, then $3000 \mathrm{kPa}$ is the critical production pressure, which is less than $4000 \mathrm{kPa}$ calculated on the basis of formation subsidence.

For reservoir with an initial hydrate saturation of $60 \%$ (the hydrate distribution mode is particle wrapping), when production pressure is $1000 \mathrm{kPa}$, the inflection point appears 


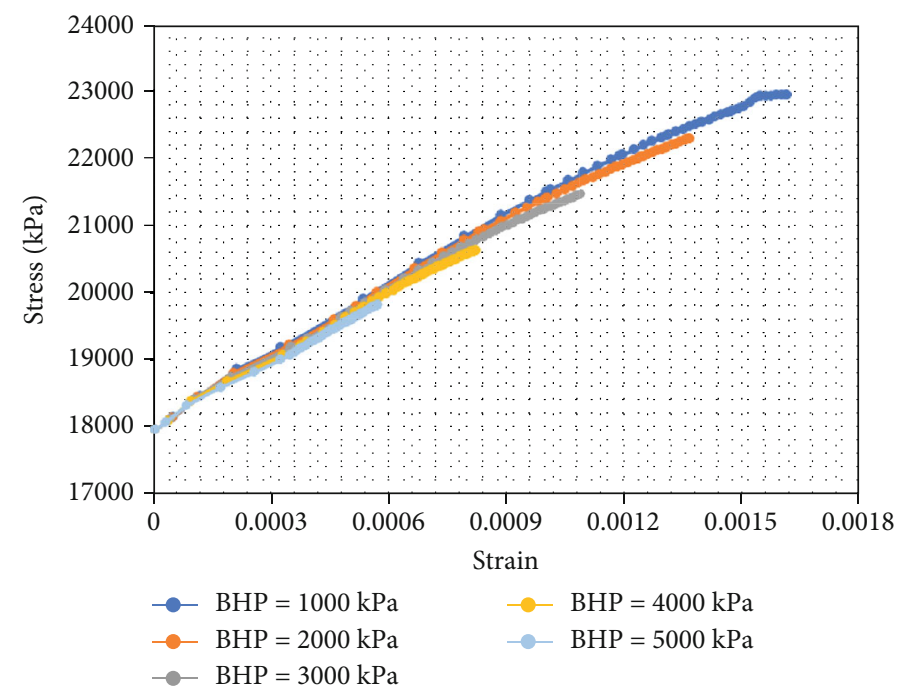

Figure 10: The stress-strain curve of particle-wrapping hydrate reservoir.

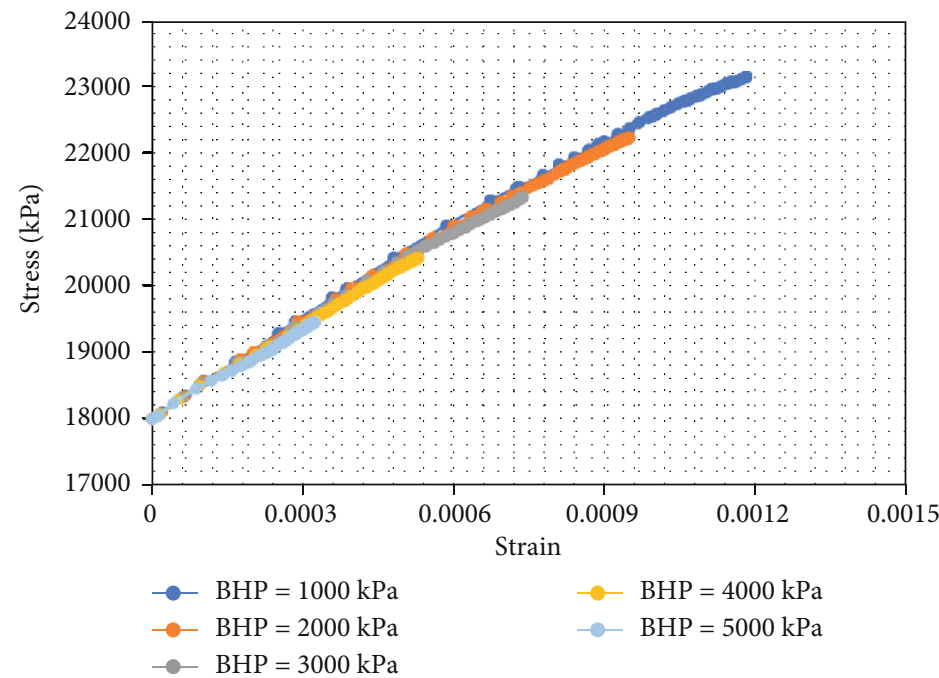

FIGURE 11: The stress-strain curve of skeleton-supporting hydrate reservoir.

in the stress-strain curve (see in Figure 10), which is considered that the formation fails. However, when production pressure is greater than $2000 \mathrm{kPa}$, there is no inflection point in the curve, then $2000 \mathrm{kPa}$ is the critical production pressure, which is less than $3000 \mathrm{kPa}$ calculated on the basis of formation subsidence.

For reservoir with an initial hydrate saturation of $70 \%$ (the hydrate distribution mode is particle supporting), when production pressure is greater than $1000 \mathrm{kPa}$, there is no inflection point in the curve (see Figure 11), then $1000 \mathrm{kPa}$ is the critical production pressure, which is less than $2000 \mathrm{kPa}$ calculated on the basis of formation subsidence.

Compared with the optimal production pressure determined based on formation subsidence in the above section, when analysis is based on stress-strain curve, the critical production pressure is smaller; thus, it is difficult to ensure formation that does not undergo large subsidence. Therefore, it is of little significance to actual production, and no subsequent analysis is conducted.

\section{Conclusions}

In this paper, production models of different types of hydrate reservoirs under different BHP were established and we drew the following conclusions through numerical simulation:

(1) Through sensitivity analysis of various parameters on formation subsidence, we obtained factors which had the most significant influence on formation subsidence, that is, BHP and hydrate saturation

(2) Whether formation fails was judged based on formation subsidence and stress-strain curve, and critical production pressure of each type of hydrate 
formation was determined. Through comparison, it was found that the judgement result based on formation subsidence was more reasonable

(3) Combining the time required for formation failure and the cumulative gas production, the optimal production pressure of different types of hydrate reservoir was determined. For reservoir with an initial hydrate saturation of $40 \%, 60 \%$, and $70 \%$, the optimal production pressure is $3000 \mathrm{kPa}, 3000 \mathrm{kPa}$, and $1000 \mathrm{kPa}$, respectively

(4) Under optimal production pressure, the cumulative gas production within 1100 days is $1.89 \times 10^{7} \mathrm{~m}^{3}$ $\left(S_{h}=40 \%\right), 4.78 \times 10^{6} \mathrm{~m}^{3}\left(S_{h}=60 \%\right)$, and $1.15 \times 10^{7}$ $\mathrm{m}^{3}\left(S_{h}=70 \%\right)$, respectively

(5) Under optimal production pressure, the safe production time is 750 days $\left(S_{h}=40 \%\right), 1100$ days $\left(S_{h}=60\right.$ $\%)$, and 940 days $\left(S_{h}=70 \%\right)$, respectively

\section{Data Availability}

The (model parameters) data used to support the findings of this study are included within the article.

\section{Conflicts of Interest}

The authors declare that there is no conflict of interest regarding the publication of this paper.

\section{Acknowledgments}

This study was funded by the National Key Research and Development Plan (No. 2019YFC0312301) and the University Fund - The Science Research Starting Foundation for Introduced Talents (No. 2462017YJRC034).

\section{References}

[1] J. Y. Lee, B. J. Ryu, T. S. Yun, J. Lee, and G. C. Cho, "Review on the gas hydrate development and production as a new energy resource," KSCE Journal of Civil Engineering, vol. 15, no. 4, pp. 689-696, 2011.

[2] Y. F. Makogon, "Hydrates of hydrocarbons," Penn Well Books, vol. 610 , no. 52, pp. 50-62, 1997.

[3] G. C. Fitzgerald and M. J. Castaldi, "Thermal stimulation based methane production from hydrate bearing quartz sediment," Industrial \& Engineering Chemistry Research, vol. 52, no. 19, pp. 6571-6581, 2013.

[4] M. H. Yousif, H. H. Abass, M. S. Selim, and E. D. Sloan, "Experimental and theoretical investigation of methane-gashydrate dissociation in porous media," SPE Reservoir Engineering, vol. 6, no. 1, pp. 69-76, 2013.

[5] S. Falser, S. Uchida, A. C. Palmer, K. Soga, and T. S. Tan, "Increased gas production from hydrates by combining depressurization with heating of the wellbore," Energy \& Fuels, vol. 26, no. 10, pp. 6259-6267, 2012.

[6] J. Priest, A. Sultaniya, and C. Clayton, "Impact of Hydrate Formation and Dissociation on the Stiffness of a Sand," in Proceedings of the 7th international conference on gas hydrates (ICGH 2011), Edinburgh, UK, 2011.
[7] J. Rutqvist, G. J. Moridis, and T. Grover, "Geomechanical response of permafrost-associated hydrate deposits to depressurization-induced gas production," Journal of Petroleum Science and Engineering, vol. 67, no. 1-2, pp. 1-12, 2009.

[8] J. Rutqvist and G. J. Moridis, "Numerical Studies on the Geomechanical Stability of Hydrate-Bearing Sediments," in Offshore Technology Conference, Houston, Texas, U.S.A, 2007.

[9] L. G. Liu, Experimental Study on Hydrate Exploitation with Different Saturation, Dalian university of technology, 2012.

[10] W. F. Waite, J. C. Santamarina, D. D. Cortes et al., "Physical properties of hydrate-bearing sediments," Reviews of Geophysics, vol. 47, no. 4, 2009.

[11] M. Hyodo, Y. Nakata, N. Yoshimoto, and T. Ebinuma, "Basic research on the mechanical behavior of methane hydratesediments mixture," Journal of Japanese Geotechnical Society, vol. 45 , no. 1 , pp. $75-85,2005$.

[12] H. Z. Wei, R. T. Yan, P. Chen, H. H. Tian, and E. L. Wu, "Triaxial testing of carbon dioxide hydrate sand with different hydrate saturation," Rock and Soil Mechanics, vol. 32, Supplement 2, pp. 198-203, 2011.

[13] G. H. Huang, Z. Su, M. S. Xia, and D. D. Wu, "Study on sand production in wells of natural gas hydrate," Marine Geology and Quaternary, vol. 37, no. 5, pp. 174-183, 2017.

[14] J. Dai, H. Xu, F. Snyder, and N. Dutta, "Detection and estimation of gas hydrates using rock physics and seismic inversion: examples from the northern deepwater Gulf of Mexico," The Leading Edge, vol. 23, no. 1, pp. 60-66, 2004.

[15] Y. F. Cheng, H. C. Shen, and Y. Z. Zhao, "Fluid-solid coupling study on the physical properties of natural gas hydrate reservoir," Acta Petroleum Sinica, vol. 31, no. 4, pp. 607-611, 2010.

[16] M. H. Yu, Numerical simulation of decomposition of methane hydrate in porous media, Dalian University of Technology, China, 2016.

[17] X. J. Sun, Experimental study on physical and mechanical properties of gas hydrate formation, China University of Petroleum, 2011.

[18] P. Varun, T. David, and K. Anjani, Quantifying the Uncertainty Associated with Caprock Integrity during SAGD Using Coupled Geomechanics Thermal Reservoir Simulation, Alberta, SPE Heavy Oil Conference-Canada, 2014. 